\title{
L. Kihindou, Négritude et fleuvitude. Et autres observations littéraires
}

\section{Roberto Ferraroni}

\section{Q OpenEdition}

1 Journals

\section{Edizione digitale}

URL: http://journals.openedition.org/studifrancesi/10081

DOI: 10.4000/studifrancesi. 10081

ISSN: 2421-5856

\section{Editore}

Rosenberg \& Sellier

\section{Edizione cartacea}

Data di pubblicazione: 1 août 2017

Paginazione: 410-411

ISSN: 0039-2944

\section{Notizia bibliografica digitale}

Roberto Ferraroni, «L. Kihindou, Négritude et fleuvitude. Et autres observations littéraires», Studi Francesi [Online], 182 (LXI | II) | 2017, online dal 01 août 2017, consultato il 09 janvier 2021. URL: http:// journals.openedition.org/studifrancesi/10081 ; DOI: https://doi.org/10.4000/studifrancesi.10081

Questo documento è stato generato automaticamente il 9 janvier 2021.

\section{(c) (i) (9)}

Studi Francesi è distribuita con Licenza Creative Commons Attribuzione - Non commerciale - Non opere derivate 4.0 Internazionale. 


\title{
L. Kihindou, Négritude et fleuvitude. Et autres observations littéraires
}

\author{
Roberto Ferraroni
}

\section{NOTIZIA}

LISS KIHINDOU, Négritude et fleuvitude. Et autres observations littéraires, Paris, L'Harmattan, 2016, 71 pp.

1 La letteratura congolese è una letteratura che può essere definita "giovane", in quanto è solo a partire dai primi anni Cinquanta che assistiamo alla nascita di opere letterarie firmate da autori originari di questa Repubblica dell'Africa centrale. Nel suo saggio, Liss Kihindou ripercorre rapidamente questa ancor breve vita letteraria, cercando di metterne in risalto i punti cardine e gli autori principali, inclusi quelli che, inspiegabilmente, vengono di solito messi in ombra dalla critica nazionale e internazionale.

2 Il saggio unisce le riflessioni dell'autrice ad alcuni suoi interventi in importanti manifestazioni tenutesi negli ultimi anni: uno risalente al 13 agosto 2010 in occasione del cinquantesimo anniversario dell'indipendenza del Congo; l'altro al 24 giugno 2014 in occasione del cinquantesimo anniversario della morte di Jean-Baptiste Tati Loutard. Il volume è idealmente diviso in tre parti: il discorso introduttivo sul panorama letterario congolese, legato all'intrinseco rapporto tra Négritude e Fleuvitude, è seguito da una parte in cui Kihindou ci presenta la letteratura del suo paese alla luce della sua esperienza diretta sia di lettrice e ammiratrice di importanti autori, che di scrittrice. Nell'ultima parte viene lasciato spazio a un'interessante riflessione sul "mercato" del libro, a partire dal processo che porta alla selezione di un testo che verrà dato alle stampe, fino alla consacrazione o meno del volume nel panorama letterario.

3 Come ci anticipa Boniface Mongo-Mboussa nella prefazione, Liss Kihindou inizia il suo saggio illustrando il significato di Négritude e Fleuvitude, mettendo in evidenza il legame esistente tra i due movimenti. Il primo, il cui padre è Aimé Césaire, afferma con 
forza la fierezza di essere congolesi e cerca di ridare valore alle origini e al patrimonio culturale di questa terra. Il secondo, invece, è un movimento che nasce nel 2013, almeno formalmente: in realtà, in effetti, l'attenzione prestata all'importante ruolo che il fiume ricopre nella letteratura, e prima ancora nella vita, del Congo, è presente fin dall'opera capostipite della produzione letteraria congolese: Coeur d'Aryenne, di Jean Malonga, pubblicata nel 1953. A partire da questo primo lavoro, tutta la letteratura del Congo pone al centro l'immagine del fiume come fonte di vita, di salvezza, come principale collegamento tra il Nord e il Sud del paese. Nella seconda parte del saggio, la narrazione assume sfumature più personali e biografiche. In apertura ci vengono presentati due autori, Sylvain Bemba e Gabriel Okoundji, attraverso aneddoti vissuti in prima persona dall'autrice. Di particolare interesse la riflessione su Bemba, autore tanto importante per la letteratura congolese, quanto "oublié" dalla critica letteraria. Kihindou cerca di sottolinearne il grande valore e di restituirgli il posto che merita tra $\mathrm{i}$ grandi autori del panorama letterario del suo paese. In chiusura di questa seconda parte, l'autrice passa dall'essere semplice lettrice, all'essere scrittrice lei stessa, raccontando e illustrando la sua novella Le Secret (ma senza svelarne il segreto), in cui la protagonista incontra i grandi autori congolesi ormai venuti a mancare. Infine, l'ultima parte tratta un argomento che, partendo dal mondo della letteratura congolese, si estende all'universo dei libri in senso lato. Ci vengono illustrati i processi di scelta, da parte delle case editrici, dei libri da pubblicare, ma anche gli ostacoli che incontrano gli autori in erba, o comunque poco conosciuti, prima di riuscire a vedere $\mathrm{i}$ loro sforzi trasformati in libri, viene sottolineata l'importanza della critica letteraria nel valorizzare o stroncare un testo, ma soprattutto ci viene presentato l'unico insindacabile giudice che determina la vittoria o la sconfitta dello scrittore: il lettore.

4 Liss Kihindou conosce profondamente la storia letteraria del suo paese d'origine e in questo saggio ci aiuta abilmente a ripercorrerne la strada, toccandone i punti cardine. Un saggio che getta luce su voci troppo a lungo dimenticate dalla critica, ma portatrici di idee, valori e desideri di un popolo che silenziosamente e lentamente ha iniziato a costruire una propria identità letteraria ben definita e di spessore nel panorama della letteratura francofona extraeuropea. 